\title{
Ranking of the Factors Affecting Productivity of Microtunneling Projects
}

\author{
Mohamed Y. Hegab, P.E. ; and Ossama M. Salem, P.E. ${ }^{2}$
}

\begin{abstract}
The need to provide utility service lines with less disruption to the ground surface has increased the demand for trenchless excavation methods like microtunneling. Although the microtunneling technique has been used in the United States since 1984, the factors influencing the success of construction process are not completely clear among industry parties. Better understanding of the factors affecting the microtunneling construction process will facilitate enhancing and modeling the productivity of microtunneling projects. A questionnaire was sent to microtunneling experts to study the factors affecting productivity and their ranked importance. The participants are contractors, engineers, and manufacturers in the United States and Canada. This paper presents the results of analyzing the responses of the experts in the microtunneling industry. This research builds up the basics for modeling the microtunneling productivity of microtunneling projects. It will help microtunneling contractors identify the most affecting factors on microtunneling productivity and then building productivity models.
\end{abstract}

DOI: $10.1061 /(\mathrm{ASCE}) \mathrm{PS} .1949-1204.0000038$

CE Database subject headings: Microtunneling; Productivity; Construction management; Questionnaires; Trenchless technology.

Author keywords: Microtunneling; Productivity; Construction; Questionnaire; Trenchless technology.

\section{Introduction}

The need for utility service lines with less disruption to the surface increased the demand for trenchless excavation methods like microtunneling. Microtunneling is a term most often applied to remotely controlled pipe jacking techniques. The definition of microtunneling is slightly different in Europe, Japan, and United States. Europe and Japan define any pipe jacking machine as a microtunneling machine based on its size. In Japan, any size below $800 \mathrm{~mm}$ is a microtunneling while in Europe the margin is 1,000 mm [Thomson 1993; International Society of Trenchless Technology (ISTT) 1999]. American contractors consider any remotely controlled guided pipe jacking machine as a microtunneling machine (Salem and Hegab 2001). The microtunneling technique can be applied in different projects such as gravity and pressure lines, permanent ducts for cables, and crossings under railways or roads.

The first microtunneling machine was developed in Japan in 1972 by Komatsu and the first job was completed in 1974. Microtunneling spread slowly but gained popularity in Europe specifically in Germany and the United Kingdom starting in 1981 and 1984, respectively (Thomson 1993). The literature shows that

\footnotetext{
${ }^{1}$ Associate Professor, Dept. of Civil Engineering and Applied Mechanics, California State Univ.-Northridge, 18111 Nordhoff St., Northridge, CA 91330-7348. E-mail: mhegab@csun.edu

${ }^{2}$ Professor, Yabroudi Endowed Chair of Sustainable Civil Infrastructures, Civil and Environmental Engineering Dept., Syracuse Univ., 151 Link Hall, Syracuse, NY 13244; formerly, Univ. of Cincinnati, P.O. Box 210071, Cincinnati, OH 45221-0071. E-mail: drosalem@gmail.com

Note. This manuscript was submitted on September 2, 2005; approved on July 29, 2009; published online on January 15, 2010. Discussion period open until July 1, 2010; separate discussions must be submitted for individual papers. This paper is part of the Journal of Pipeline Systems Engineering and Practice, Vol. 1, No. 1, February 1, 2010. CASCE, ISSN 1949-1190/2010/1(1)/42/11/\$25.00.
}

microtunneling started in the United States around 1984 and since that time, rapid growth in microtunneling use has been recorded (Atalah and Hadala 1996). Rapid growth of microtunneling is expected in urban areas because of the high benefit-cost ratio of microtunneling compared to open cut methods. Compared to open cut methods, microtunneling has better traffic control, lower reinstatement costs, less need to dig around existing utilities, and lower social cost. The low social cost results from the fact that microtunneling reduces traffic delay time and disruption of commercial activities (McKim 1997).

\section{Background and Significance}

Microtunneling contractors strive to increase profitability through increased productivity. Modeling of microtunneling productivity is difficult because of the large number of factors involved.

Nido (1999) studied the factors affecting productivity based on expert's opinion. A questionnaire was sent to six experts asking for their opinion about factors affecting productivity, but the questions presented in this reference did not ask about the importance or significance of each factor. Furthermore, it did not attempt to classify the importance of the factors nor examining relations among them. Table 1 shows the factors affecting microtunneling productivity, as identified by Nido (1999).

Understanding the relative importance of each factor is essential to model and predict microtunneling productivity. This paper presents the results of a conducted survey that studied, in more depth, the factors affecting productivity of microtunneling including the dependency between these factors. The results of the survey were reported under three categories that include factors affecting productivity, dependency between the factors, and favorable soil conditions.

The main objective of the conducted survey is to identify the most important factors affecting the microtunneling process productivity based on the expert opinion of contractors, engineers, 
Table 1. Proposed Microtunneling Productivity Factors

\begin{tabular}{ll}
$\begin{array}{l}\text { Factor } \\
\text { number }\end{array}$ & \multicolumn{1}{c}{\begin{tabular}{c}
\multicolumn{1}{c}{ Factors affecting productivity } \\
(Nido 1999)
\end{tabular}} \\
\hline 1 & Cutter head \\
2 & Crew/operator experience \\
3 & Soil conditions \\
4 & Drive length \\
5 & Separation equipment \\
6 & Pipe section length \\
7 & Shaft design (size, layout, structural integrity) \\
8 & Slurry flow rate \\
9 & Pipe material \\
10 & Use of IJS \\
11 & Use of high pressure water jets at the excavation face \\
12 & (jetting) \\
13 & Accurate geotechnical investigations \\
14 & Depth of installation \\
15 & Groundwater conditions \\
16 & Appropriateness of the MTBM \\
17 & Obstruction or unusual soil conditions \\
18 & Restrictions to working hours \\
19 & Straight versus curved alignment \\
20 & Technical support \\
\hline
\end{tabular}

and manufacturers in the microtunneling industry. Identifying these factors is expected to help in improving the productivity of microtunneling construction process by planning and executing a more efficient microtunneling operation.

\section{Pilot Survey}

A pilot survey was conducted by the phone to investigate the factors affecting productivity. Ten experts of almost 20 years in the area of microtunneling were asked to list factors that affect productivity. Each expert mentioned a number of factors that combined into 22 factors. The pilot survey results were compared against Nido's findings (Nido 1999). They agreed on what Nido (1999) found and added two more factors, jacking thrust and cutter head torque. The 22 factors were considered in the questionnaire.

\section{Microtunneling Questionnaire}

A questionnaire was distributed to microtunneling contractors, engineers, and manufacturers to investigate the factors affecting microtunneling productivity. The questionnaire was divided into four sections. The first section contained questions about respondents' contact information and type of business. The second section asked about productivity factors and respondents' workrelated experience. In the third section, the respondent was asked about the possible dependency between the various productivity factors. The final section addressed favorable soil conditions for the microtunneling operation.

The questionnaire was sent to 82 microtunneling contractors, engineers, and manufacturers across the United States and Canada. Additionally, the questionnaire was posted on the internet with interactive form, and a notification was sent to the microtun- neling experts by e-mail. A copy of the questionnaire is shown in Appendix I. The questionnaire asked the participants to rank the factors that affect productivity of microtunneling machines. The ranking was scaled from 1 to 5 , where 1 is not important and 5 is extremely important. The questionnaire asked also a question about the ranking of the favorable soil conditions in microtunneling operations. Similarly, the ranking was scaled from 1 to 5 , where 1 is least favorable condition and 5 is most favorable. Twenty-seven responses were received, representing a response rate of $33 \%$. Accordingly, the researchers are $95 \%$ certain that the rankings of the factors represent the population opinion with confidence interval of $\pm 15 \%$ around the mean (Thompson and Seber 1996). Four of the respondents answered only parts of the questionnaire, so their answers were eliminated from the final analysis. The experience of the respondents in the microtunneling industry ranged from 3 to 20 years with an average of 8 years. The respondents to the questionnaire were eight contractors, two subcontractors, eight engineers, and five manufacturers. Contractors, subcontractors, engineers, and manufacturers had comparable responses, which came from their experience as all the respondents had at least 3 years experience in the microtunneling field.

\section{Factors Affecting Productivity}

Based on the literature review and interviews with experts in the field, 20 factors were identified and listed in the questionnaire. Additionally, a pilot survey, which was conducted to validate $\mathrm{Ni}$ do's suggested factors gave the participants the opportunity to add or delete factors (by selecting " 1 " out of the 1-5 scale). Consequently, two additional factors were added to the initial list. Furthermore, the questionnaire asked the respondents to rank the importance of each factor. The score for each factor was obtained by taking the average score of responses for each factor. A glossary is shown in Appendix II to explain some of the terms used by the microtunneling industry.

\section{Experience Weights}

Questionnaire recipients were selected carefully based on their knowledge and working experience with the microtunneling industry. According to the respondents' number of years of experience, a weight was assigned to each response to reflect the level of experience. The final score of each factor was calculated twice, with and without experience weight. The experience weights were applied to the responses as follows:

$$
\mathrm{WAVR}_{j}=\frac{\sum_{i=1}^{n} E_{i} R_{i j}}{\sum_{i=1}^{n} E_{i}}
$$

where $\mathrm{WAVR}_{j}=$ weighted average of the $j$ th factor; $E_{i}$ $=$ experience of participating expert " $i$ " (years); $R_{i j}=$ rating of expert $i$ of $j$ th factor (1-5); and $n=$ number of participating experts.

Ranking of variables' importance can be conducted by a number of statistical techniques. The appropriate technique should be selected based on the nature of the problem and the required outcomes. The maximum utility model and hypothesis analysis are widely used in pairwise comparison on survey analysis while techniques such as Bradley-Terry and logit models are rarely used. The maximum utility model gives a value of 1 for the item of maximum value and a value of "0" otherwise. Bradely-Terry 
Table 2. Productivity Factors from Questionnaire

\begin{tabular}{|c|c|c|c|c|c|c|c|}
\hline Factor & Notation & Number & Explanation & Measure & $\begin{array}{l}\text { Weighted } \\
\text { scale }\end{array}$ & $\begin{array}{l}\text { Absolute } \\
\text { deviation }\end{array}$ & $\begin{array}{l}\text { Row } \\
\text { scale }\end{array}$ \\
\hline Soil condition & ST & 3 & Actual soil type & Sand, clay, silt & 4.77 & 0.45 & 4.70 \\
\hline $\begin{array}{l}\text { Geotechnical } \\
\text { investigation }\end{array}$ & GI & 12 & $\begin{array}{l}\text { Intensive borings helps in recognizing } \\
\text { the soil type }\end{array}$ & Intensive, shallow & 4.73 & 0.39 & 4.74 \\
\hline Operator experience & $\mathrm{E}$ & 2 & Operator's and crew experience in similar projects & Low, high & 4.48 & 0.54 & 4.52 \\
\hline Obstructions & $\mathrm{O}$ & 16 & Existence of obstruction during tunneling & $\mathrm{Y} / \mathrm{N}$ & 4.43 & 0.58 & 4.55 \\
\hline Lubrication & $\mathrm{L}$ & 20 & Using of lubrication during tunneling & $\mathrm{Y} / \mathrm{N}$ & 4.16 & 0.68 & 4.22 \\
\hline Torque $^{\mathrm{a}}$ & $\mathrm{T}$ & 22 & Rotating cutter torque & $\mathrm{KNM}(\mathrm{lb} \cdot \mathrm{ft})$ & 4.10 & 0.38 & 4.25 \\
\hline Jacking thrust ${ }^{\mathrm{a}}$ & $\mathrm{P}$ & 21 & Jacking thrust and its maximum limit & $\mathrm{KN}$ & 4.00 & 0.0 & 4.00 \\
\hline Separation equipment & SE & 5 & Configuration of separation equipment & Number of stages & 3.86 & 0.85 & 3.87 \\
\hline Curved alignment & $\mathrm{SC}$ & 18 & Existence of curved alignment & $\%$ of curves & 3.83 & 0.96 & 3.83 \\
\hline M/T type & M & 15 & Using the appropriate machine (slurry or EPB) & Slurry or EPB & 3.78 & 0.65 & 3.86 \\
\hline Cutter shape & $\mathrm{C}$ & 1 & Shape of the cutting tool & Teeth, disks, mixed & 3.72 & 0.99 & 3.86 \\
\hline Drive length & $\mathrm{D}$ & 4 & The tunneling length & $\mathrm{M}(\mathrm{ft})$ & 3.59 & 0.72 & 3.70 \\
\hline Use of IJS & IJ & 10 & Using IJS to increase jacking length & $\mathrm{Y} / \mathrm{N}$ & 3.47 & 0.81 & 3.48 \\
\hline Technical support & TS & 19 & $\begin{array}{l}\text { Existence of representative of } \\
\text { machine's manufacturer }\end{array}$ & $\mathrm{Y} / \mathrm{N}$ & 3.36 & 0.82 & 3.36 \\
\hline Working hours & W & 17 & Number of shifts per day & $1,2,3$ & 3.34 & 0.86 & 3.32 \\
\hline Slurry rate & $\mathrm{S}$ & 8 & Pumping rate of slurry during tunneling & M3/HR & 3.28 & 0.74 & 3.39 \\
\hline Water jetting & $\mathrm{J}$ & 11 & Using of jets in front of head & $\mathrm{Y} / \mathrm{N}$ & 3.15 & 0.90 & 3.26 \\
\hline Shaft design & SD & 7 & Shaft size and shape & Narrow, wide & 2.95 & 0.69 & 3.13 \\
\hline Ground water & GW & 14 & Existence of ground water during tunneling & Above, below, through & 2.88 & 0.75 & 3.17 \\
\hline Pipe length & PL & 6 & The used pipe length & Short, long & 2.79 & 0.84 & 3.04 \\
\hline Pipe material & PM & 9 & Material type of jacked pipe & $\begin{array}{l}\text { VCP, concrete, steel, } \\
\text { GRP, PVC }\end{array}$ & 2.72 & 0.81 & 2.91 \\
\hline Installation depth & ID & 13 & How deep is the pipe underground & Deep, shallow & 2.48 & 0.81 & 2.70 \\
\hline
\end{tabular}

${ }^{\mathrm{a}}$ These factors are introduced by the pilot survey.

and logit models do not always choose the most preferred item (Finkbeiner and Stevens 1988). Accordingly, the hypothesis analysis method is the most appropriate method in this research.

A hypothesis analysis was conducted to determine whether there is any significant difference between the weighted and raw means or not. In other words, the result of the test determines whether to use the weighted average in representing the experts' opinion. Pair $t$-test (student test) was used for comparison of mean values. The hypothesis was formulated as follows:

$$
\begin{aligned}
& H_{o}: \mu_{1}=\mu_{2} \\
& H_{1}: \mu_{1} \neq \mu_{2}
\end{aligned}
$$

where $\mu_{1}=$ average of raw response for each question and $\mu_{2}$ $=$ average of weighed response for each question.

At $95 \%$ confidence interval, the $t$ value was ranged from 0.0474 to 0.1328 where the calculated $t$ value test was 4.39 . Therefore, the null hypothesis that the weighted and raw averages are the same was rejected. To represent the variance in expert's opinions, mean absolute deviation (MAD) was used. MAD is defined as the arithmetic mean of all the distances of data points from the average (Huber 1981). MAD is used to represent how the responses are different from their average. MAD is a better indicator to the difference between the data points and their average than the standard deviation because it gives the absolute distance not the square one. The results of Eq. (2) are provided in Table 2 and Fig. 1

$$
\operatorname{MAD}_{j}=\frac{\sum_{i=1}^{n_{j}}\left|x_{i j}-\bar{x}_{j}\right|}{n_{j}}
$$

where $\mathrm{MAD}_{j}=\mathrm{MAD}$ for $j$ th factor; $x_{i j}=$ response of $i$ th participant for $j$ th factor; $\bar{x}_{j}=$ average of responses for the $j$ th factor; and $n_{j}=$ number of responses for the $j$ th factor.

\section{Soil Conditions}

Based on participants' responses, soil conditions, accurate geotechnical investigations, crew experience, obstructions, cutter head torque, use of lubrications, and capacity of main jacks were found to be the most affecting factors on microtunneling productivity. Soil investigation and soil conditions are the driving factors in microtunneling projects. Accurate expectation of soil conditions results from more intensive soil investigations and, accordingly, better estimate of project productivity. The soil condition factor had an average score of 4.77 with MAD of 0.45 , which was the highest ranked factor affecting microtunneling operation. The MAD of 0.45 indicates that participants' opinions ranged 0.45 around the average score. The microtunneling machine productivity is affected by the interaction between the soil and machine. The penetration rate of the machine changes according to the soil type. Accordingly, the contractor should check the expected soil well before bidding the project. The importance of geotechnical investigations shows up in this phase.

Geotechnical investigations are the traditional way to determine the soil conditions. Geotechnical investigation's average 


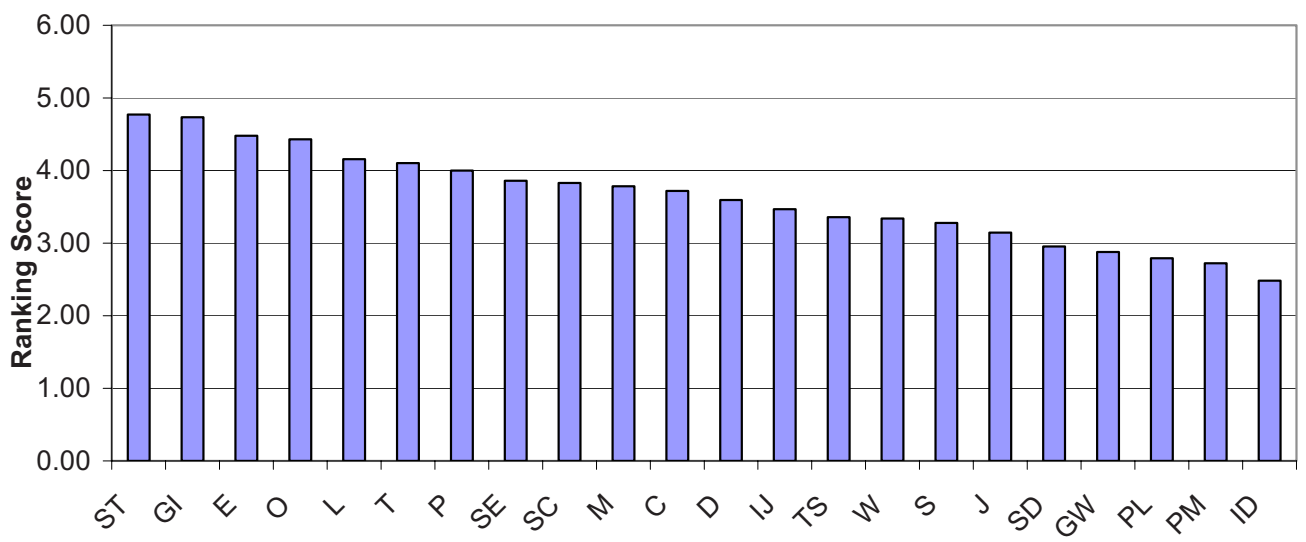

Fig. 1. Questionnaire responses for the most affecting factors on microtunneling productivity

score was 4.73 with MAD of 0.39 , which reflected its importance. The accurate and intensive soil investigations are essential for any underground job. Accordingly, increasing the number of boreholes decreases the risk of unforeseen conditions.

\section{Crew and Operator's Experience}

The third most important factor was "crew and operator's experience" with an average score of 4.48 and MAD of 0.54. Crew and operator experience were put together because they represent the human factor in the operation. However, the writers believe that operator's experience is much more relevant. The operator's experience with the equipment can affect the productivity. The experience of the operator plays an important role in overcoming some problems that need quick and appropriate action.

Additionally, the crew's experience is important in reducing pipe preparation time. The preparation time includes the consumed time to prepare the pipe outside the pit and test it, hook the slurry lines, and adjust the jacks in the pit. The preparation time varies according to the crew's experience. The contractor should try to use the same crew as long as possible because repeating the same procedure increases the rate of their learning curve and hence improves the productivity.

\section{Obstructions}

An obstruction is any element that covers part or all of the cross section of the microtunneling machine and prevents its progress [ISTT 1999]. Obstructions had an average score of 4.43 with MAD of 0.58 . The risk of obstruction or unusual soil condition existence is the result of poor geotechnical investigations. Although extensive geotechnical investigations increase the certainty about underground soil conditions, they cannot identify all obstructions. Additional geological and historical information about the area can help in predicting the existence of some obstructions like old building foundations. Obstructions and unusual conditions can affect the productivity negatively.

\section{Cutter Head Torque}

Cutter head torque was the next factor in its importance to microtunneling productivity with an average score of 4.1 and MAD of 0.38 . Two hydraulic systems are controlling the progress of microtunneling machine. One of them is responsible for jacking and the other for cutter head torque. The cutter head is responsible for cutting into the soil when it rotates using teeth or cutting disks. Increasing the torque applied on the cutter head usually increases its ability to cut through harder soil.

\section{Lubrication}

Use of lubrication and its rate of application are important in enhancing the performance of the microtunneling machine. Lubrication decreases the friction between the machine and the soil. Accordingly, lubrication increases the efficiency of the machine because it decreases the torque losses due to friction. Use of lubrication was scored an average of 4.16 and a MAD of 0.68 .

\section{Capacity of Main Jacks}

Capacity of main jacks controls the maximum allowable drive length in most of the cases. Increasing the drive length reduces the mobilization periods between drives and accordingly increases the overall productivity. Capacity of main jacks was scored an average of 4.0 and a MAD of zero.

\section{Importance of Factors}

To be able to further analyze the results, the studied factors were categorized under four categories: underground conditions, operator's experience, mechanics of the system, and others. As concluded from the questionnaire responses, the most important category was found to be the underground conditions followed by the operator's experience and finally the mechanics of the system. Underground conditions include accurate geotechnical reports, soil conditions, and obstructions. Operators' experience can be a major factor in productivity improvement because many of the problems can be overcome consequently. The mechanics of the system was represented by the cutter head torque, capacity of main jacks, and lubrication. Lubrication can be included in this group because it is mainly used to overcome the soil friction. Other factors, which come next, can enhance the performance of the project but their impact is less than the first three groups according to the survey.

\section{Dependency between Factors}

Dependency between factors has been studied to gain an understanding of their relationships. The dependency between the various factors was not considered in their ranking. This dependency is one of the reasons behind the difficulty of modeling the productivity of microtunneling projects. For better understanding of the effect of the previously mentioned factors on productivity, the respondents were asked to provide their expert opinion on the relationships and dependencies of various factors on each other. 
Table 3. Values of $\chi^{2}$ for Different Factor Combinations

\begin{tabular}{|c|c|c|c|c|c|c|c|c|c|c|c|c|c|c|c|c|c|c|c|c|c|c|}
\hline $\begin{array}{l}\text { Number }^{\mathrm{a}} \\
\text { notation }\end{array}$ & & $\begin{array}{l}2 \\
\mathrm{E}\end{array}$ & $\begin{array}{c}3 \\
\text { ST }\end{array}$ & $\begin{array}{l}4 \\
\mathrm{D}\end{array}$ & $\begin{array}{c}5 \\
\text { SE }\end{array}$ & $\begin{array}{c}6 \\
\text { PL }\end{array}$ & $\begin{array}{c}7 \\
\text { SD }\end{array}$ & $\begin{array}{l}8 \\
S\end{array}$ & $\begin{array}{c}9 \\
\text { PM }\end{array}$ & $\begin{array}{l}10 \\
\mathrm{IJ}\end{array}$ & $\begin{array}{c}11 \\
\mathrm{~J}\end{array}$ & $\begin{array}{l}12 \\
\text { GI }\end{array}$ & $\begin{array}{l}13 \\
\text { ID }\end{array}$ & $\begin{array}{c}14 \\
\mathrm{GW}\end{array}$ & $\begin{array}{l}15 \\
M\end{array}$ & $\begin{array}{l}16 \\
\mathrm{O}\end{array}$ & $\begin{array}{l}17 \\
W\end{array}$ & $\begin{array}{l}18 \\
\text { SC }\end{array}$ & $\begin{array}{l}19 \\
\text { TS }\end{array}$ & $\begin{array}{c}20 \\
\mathrm{~L}\end{array}$ & $\begin{array}{c}21 \\
\mathrm{P}\end{array}$ & $\begin{array}{c}22 \\
\mathrm{~T}\end{array}$ \\
\hline 1 & $\mathrm{C}$ & 3.6 & 104.7 & 1.3 & 0.0 & 3.6 & 3.6 & 5.5 & 3.6 & 3.6 & 3.0 & 1.3 & 3.6 & 0.0 & 3.0 & 3.0 & 1.7 & 1.7 & 0.5 & 1.7 & 3.6 & 3.6 \\
\hline 2 & $\mathrm{E}$ & & 4.4 & 0.1 & 2.0 & 0.7 & 2.0 & 2.0 & 0.1 & 0.1 & 0.1 & 0.7 & 0.7 & 0.7 & 0.8 & 4.4 & 0.8 & 7.2 & 14.8 & 0.1 & 2.0 & 4.0 \\
\hline 3 & ST & & & 3.3 & 17.4 & 8.4 & 0.3 & 3.3 & 1.0 & 3.3 & 17.4 & 1.8 & 1.0 & 0.0 & 10.4 & 0.0 & 3.8 & 1.0 & 2.2 & 10.4 & 8.4 & 8.4 \\
\hline 4 & $\mathrm{D}$ & & & & 4.0 & 4.4 & 0.8 & 2.0 & 4.4 & 83.1 & 4.0 & 0.1 & 2.0 & 4.0 & 4.4 & 0.1 & 0.1 & 0.1 & 0.7 & 14.8 & 4.0 & 4.0 \\
\hline 5 & SE & & & & & 1.5 & 1.5 & 42.8 & 1.5 & 0.1 & 0.1 & 32.2 & 1.5 & 9.5 & 0.2 & 1.8 & 1.5 & 1.5 & 0.1 & 1.5 & 1.5 & 1.5 \\
\hline 6 & PL & & & & & & 38.8 & 2.0 & 60.3 & 0.4 & 2.0 & 0.4 & 0.0 & 2.0 & 0.4 & 2.0 & 0.4 & 29.9 & 2.0 & 0.0 & 2.0 & 2.0 \\
\hline 7 & SD & & & & & & & 1.3 & 2.9 & 1.3 & 1.3 & 7.0 & 41.1 & 12.9 & 0.0 & 0.0 & 0.0 & 0.0 & 0.0 & 1.3 & 1.3 & 1.3 \\
\hline 8 & $\mathrm{~S}$ & & & & & & & & 0.7 & 0.7 & 2.7 & 8.4 & 0.7 & 17.2 & 2.7 & 2.7 & 0.7 & 0.7 & 0.7 & 0.2 & 0.7 & 0.7 \\
\hline 9 & $\mathrm{PM}$ & & & & & & & & & 0.0 & 1.0 & 1.2 & 1.2 & 0.0 & 1.2 & 1.0 & 0.0 & 40.1 & 1.0 & 10.2 & 1.0 & 1.0 \\
\hline 10 & IJ & & & & & & & & & & 0.9 & 20.8 & 0.9 & 0.9 & 1.6 & 1.6 & 1.6 & 1.6 & 0.0 & 12.0 & 0.9 & 0.9 \\
\hline 11 & $\mathrm{~J}$ & & & & & & & & & & & 2.5 & 0.2 & 0.2 & 2.5 & 32.4 & 0.2 & 0.2 & 0.2 & 0.2 & 0.2 & 0.2 \\
\hline 12 & GI & & & & & & & & & & & & 1.0 & 10.2 & 1.2 & 54.4 & 1.0 & 1.0 & 4.6 & 4.6 & 1.0 & 1.0 \\
\hline 13 & ID & & & & & & & & & & & & & 49.7 & 5.9 & 0.8 & 0.4 & 0.4 & 0.4 & 0.8 & 0.4 & 0.4 \\
\hline 14 & GW & & & & & & & & & & & & & & 56.9 & 0.4 & 0.4 & 0.4 & 0.4 & 18.3 & 0.4 & 0.4 \\
\hline 15 & $\mathrm{M}$ & & & & & & & & & & & & & & & 39.1 & 0.4 & 0.4 & 12.0 & 0.4 & 0.5 & 0.5 \\
\hline 16 & $\mathrm{O}$ & & & & & & & & & & & & & & & & 0.1 & 0.1 & 8.6 & 8.6 & 0.1 & 0.1 \\
\hline 17 & W & & & & & & & & & & & & & & & & & 0.2 & 0.2 & 96.2 & 0.2 & 0.2 \\
\hline 18 & $\mathrm{SC}$ & & & & & & & & & & & & & & & & & & 24.3 & 5.2 & 0.1 & 0.1 \\
\hline 19 & $\mathrm{TS}$ & & & & & & & & & & & & & & & & & & & 0.0 & 0.0 & 0.0 \\
\hline 20 & $\mathrm{~L}$ & & & & & & & & & & & & & & & & & & & & 0.0 & 0.0 \\
\hline 21 & $\mathrm{P}$ & & & & & & & & & & & & & & & & & & & & & 0.0 \\
\hline 22 & $\mathrm{~T}$ & & & & & & & & & & & & & & & & & & & & & \\
\hline
\end{tabular}

${ }^{\mathrm{a}}$ The numbers are the factor numbers from Table 2.

\section{Responses Analysis}

The dependencies among the various factors (variables) were calculated based upon respondent's experience. Each respondent selected one or more dependent factors for each factor $(i)$. To identify the relationships between factors, dependency scores for each factor $(i)$ were accumulated giving an overall score of dependency for factor $(i)$.

Experts' opinions about dependencies between any two factors $(i)$ and $(j)$ were accumulated. For each factor $(i)$ the dependency scores with other factors were calculated. The responses were analyzed and the relative dependency among various factors is shown in Table 3. Each respondent selected dependent factors for each factor $i$. For the analysis purpose, each participant was considered to say "Yes" or "No" for the dependency between any two factors $i$ and " $j$." The responses were analyzed using chi-square test for contingency tables (Bain and Engelhardt 1992). In this technique the hypothesis analysis is performed as follows:

$$
\begin{aligned}
& H_{o}: p_{1}=p_{2} \\
& H_{1}: p_{1} \neq p_{2}
\end{aligned}
$$

where $p_{1}=$ proportion of participants who agreed that there is dependency between factors $i$ and $j ; p_{2}=$ proportion of participants who did not agree that there is dependency between factors $i$ and $j ; i=$ code number of the studied factor (shown in rows); and $j=$ code number of the suggested dependent factors (shown in columns).

At $95 \%$ confidence interval, chi-square value for one degree of freedom was $\chi_{0.05}^{2}(1)=3.841$. The chi-square test value should be compared to the actual chi-square values to accept or reject the previously mentioned hypothesis, as shown in Eq. (3). The chi-square values for the different combinations of factors $i$ and $j$ were calculated, as shown in Eq. (4).

$$
\begin{aligned}
& \text { Reject } H_{o} \text { if } \chi^{2}>\chi_{0.25}^{2}(1) \\
& \chi_{i j}^{2}=\frac{\left(O_{i j}-E_{i j}\right)^{2}}{E_{i j}}=\frac{\left[O_{i j}(y)-E_{i j}(y)\right]^{2}}{E_{i j}(y)}+\frac{\left[O_{i j}(n)-E_{i j}(n)\right]^{2}}{E_{i j}(n)}
\end{aligned}
$$

where $\chi_{i j}^{2}=$ chi-square value for the dependency between factors $i$ and $j ; O_{i j}=$ observed (actual) proportion of participants that have the same opinion about the dependency between factors $i$ and $j$; $E_{i j}=$ expected proportion of participants that have the same opinion about the dependency between factors $i$ and $j ; O_{i j}(y)$ $=$ observed (actual) proportion of participants that agreed that there is dependency between factors $i$ and $j ; O_{i j}(n)=$ observed (actual) proportion of participants that disagreed that there is dependency between factors $i$ and $j$; and $E_{i j}(y)=$ expected proportion of participants that could agree that there is dependency between factors $i$ and $j$.

To calculate the expected votes that agreed or disagreed on the dependency between factors, Eqs. (5)-(7) were used as follows:

$$
E_{i j}(y)=\frac{n_{j} \sum_{i=1}^{N} O_{i}(y)}{\left[n_{j}(N-1)-\sum_{i=1}^{N} O_{i}(y)\right]}
$$

$$
E_{i j}(n)=\frac{n_{j} \sum_{i=1}^{N} O_{i}(n)}{\left[n_{j}(N-1)-\sum_{i=1}^{N} O_{i}(n)\right]}
$$


Table 4. Existing Factor Dependencies; Values Are Positive Results of $\chi^{2}-\chi_{0.05}^{2}(1)$

\begin{tabular}{|c|c|c|c|c|c|c|c|c|c|c|c|c|c|c|c|c|c|c|c|c|c|c|c|}
\hline Number $^{\mathrm{a}}$ & & 1 & 2 & 3 & 4 & 5 & 6 & 7 & 8 & 9 & 10 & 11 & 12 & 13 & 14 & 15 & 16 & 17 & 18 & 19 & 20 & 21 & 22 \\
\hline notation & 1 & $\mathrm{C}$ & E & ST & $\mathrm{D}$ & SE & PL & SD & $S$ & PM & IJ & $\mathrm{J}$ & GI & ID & GW & M & $\mathrm{O}$ & W & $\mathrm{SC}$ & TS & $\mathrm{L}$ & $\mathrm{P}$ & $\mathrm{T}$ \\
\hline 1 & $\mathrm{C}$ & & & 100.9 & & & & & 1.6 & & & & & & & & & & & & & & \\
\hline 2 & $\mathrm{E}$ & & & 0.5 & & & & & & & & & & & & & 0.5 & & 3.3 & 11.0 & & & 0.2 \\
\hline 3 & ST & & & & & 13.6 & 4.5 & & & & & 13.6 & & & & 6.6 & & & & & 6.6 & 4.5 & 4.5 \\
\hline 4 & $\mathrm{D}$ & & & & & 0.2 & 0.5 & & & 0.5 & 79.3 & 0.2 & & & 0.2 & 0.5 & & & & & 11.0 & 0.2 & 0.2 \\
\hline 5 & SE & & & & & & & & 38.9 & & & & 28.4 & & 5.7 & & & & & & & & \\
\hline 6 & PL & & & & & & & 35.0 & & 56.4 & & & & & & & & & 26.0 & & & & \\
\hline 7 & SD & & & & & & & & & & & & 3.2 & 37.2 & 9.0 & & & & & & & & \\
\hline 8 & $\mathrm{~S}$ & & & & & & & & & & & & 4.6 & & 13.3 & & & & & & & & \\
\hline 9 & PM & & & & & & & & & & & & & & & & & & 36.2 & & 6.3 & & \\
\hline 10 & IJ & & & & & & & & & & & & 17.0 & & & & & & & & 8.1 & & \\
\hline 11 & $\mathrm{~J}$ & & & & & & & & & & & & & & & & 28.5 & & & & & & \\
\hline 12 & GI & & & & & & & & & & & & & & 6.3 & & 50.6 & & & 0.8 & 0.8 & & \\
\hline 13 & ID & & & & & & & & & & & & & & 45.8 & 2.0 & & & & & & & \\
\hline 14 & GW & & & & & & & & & & & & & & & 53.1 & & & & & 14.5 & & \\
\hline 15 & $\mathrm{M}$ & & & & & & & & & & & & & & & & 35.3 & & & 8.1 & & & \\
\hline 16 & $\mathrm{O}$ & & & & & & & & & & & & & & & & & & & 4.8 & 4.8 & & \\
\hline 17 & W & & & & & & & & & & & & & & & & & & & & 92.4 & & \\
\hline 18 & $\mathrm{SC}$ & & & & & & & & & & & & & & & & & & & 20.5 & 1.3 & & \\
\hline 19 & TS & & & & & & & & & & & & & & & & & & & & & & \\
\hline 20 & $\mathrm{~L}$ & & & & & & & & & & & & & & & & & & & & & & \\
\hline 21 & $\mathrm{P}$ & & & & & & & & & & & & & & & & & & & & & & \\
\hline 22 & $\mathrm{~T}$ & & & & & & & & & & & & & & & & & & & & & & \\
\hline Number o & th factors & 2 & 5 & 9 & 10 & 5 & 5 & 4 & 4 & 4 & 3 & 3 & 8 & 3 & 8 & 6 & 6 & 1 & 5 & 5 & 9 & 2 & 3 \\
\hline
\end{tabular}

${ }^{\mathrm{a}}$ The numbers are the factor numbers from Table 2.

$$
\sum_{i=1}^{N} O_{i}(n)=n_{j}(N-1)-\sum_{i=1}^{N} O_{i}(y)
$$

where $n_{j}=$ number of survey participants (voters); $\sum_{i=1}^{N} O_{i}(y)$ $=$ summation of actual agreement votes that there is dependency between factor $i$ and other factors; and $\sum_{i=1}^{N} O_{i}(y)=$ summation of actual disagreement votes that there is dependency between factor $i$ and other factors.

Therefore, the null hypothesis was checked for the combinations between each factor $i$ and $j$. For example, the dependency between Factors 1 and 3 can be calculated as follows.

The number of votes from survey respondents that mention that Factor 1 has a dependency on another factor is cumulated in a table giving $\sum_{i=1}^{N} O_{i}(y)=66$. The table had Factor 1 in a row and the other 22 factors in columns $(N=22)$. Accordingly, the cumulative number of disagreement votes for the dependency of Factor 1 on other factors was $\sum_{i=1}^{N} O_{i}(n)=23 \times 21-66=417$. Each cell of this table represents the number of agreement votes for dependency between Factors 1 and "3" (18 votes). Additionally, some respondents mentioned Factor 1 as dependent on another factor $\left(O_{31}=2\right.$ votes $)$. These cases were added to the dependency between Factor 1 and Factor 3 giving $O_{13}(y)=20$. Accordingly, the disagreement votes were considered to be $O_{13}(n)=23$ $-O_{13}(y)=3$. The expected value for agreement votes that there is a dependency between Factors 1 and 3 was calculated using Eq. (5) $\left[E_{13}(y)=23 \times 66 / 483=3.14\right]$. Similarly, the expected value for disagreement votes that there is a dependency between Factors 1 and 3 was calculated using Eqs. (6) and (7) $\left[E_{13}(n)\right.$ $=23 \times 417 / 483=19.86]$. The value of chi-square $\left(\chi^{2}\right)$ for the dependency between Factors 1 and 3 was calculated as in Eq. (4) $\left[\chi^{2}=(3.14-20)^{2} / 3.14+(19.86-3)^{2} / 19.86=104\right]$. The null hypothesis was rejected because chi-square value $\left(\chi^{2}=104\right)$ was greater than the test value $\left[\chi_{0.05}^{2}(1)=3.841\right]$. Accordingly, there is dependency between Factors 1 and 2. Values for chi-square for different combinations of factors are shown in Table 3 . Positive differences between $\chi^{2}$ and $\chi_{0.05}^{2}(1)$ for different factor combinations indicating dependency are shown in Table 4 . The higher the difference the higher the dependency is.

Some of the existing dependencies between factors are explained below. The cutting head shape is dependent on soil condition and slurry flow rate. In other words, cutter heads with different shapes should be used with different soil types to improve productivity. Slurry flow rate is also affected by the cutter head shape, which means that there is a dependency between soil condition, slurry flow rate, and cutter head shape. Similarly, different relationships can be estimated from the dependency values in Table 3. Interpretations of some of these relations, which have the highest dependency, are as follows.

The operator's experience is affected by the technical support. Soil conditions affect the use of water jets and the type of separation equipment. Drive length is affected by the use of intermediate jacking stations (IJSs) and the use of lubrications. Separation equipment selection is affected by the slurry flow rate and the accurate geotechnical investigations.

The selection of pipe section length is affected by the shaft dimensions, pipe material, and existence of curves during tunneling. The shaft design is affected by the depth of installation and ground water conditions. Slurry flow rate is affected by the existence of accurate geotechnical investigations and ground water conditions. Pipe material is affected by the existence of curved alignment and the use of lubrication. Use of IJS depends on the existence of accurate geotechnical investigations and the use of lubrication. 
Table 5. Favorable Soil Conditions with respect to Microtunneling

\begin{tabular}{lcc}
\hline $\begin{array}{l}\text { Soil } \\
\text { condition }\end{array}$ & Score & $\begin{array}{c}\text { Absolute } \\
\text { deviation }\end{array}$ \\
\hline Sand & 4.09 & 0.95 \\
Silt & 3.41 & 0.90 \\
Silty clay & 3.09 & 0.67 \\
Hard clay & 3.05 & 1.14 \\
Soft clay & 3.05 & 0.55 \\
Backfill & 2.00 & 0.76 \\
Boulders & 1.81 & 0.94 \\
\hline
\end{tabular}

The use of water jets is affected by the existence obstructions or unusual soil condition, using appropriate machine for the soil. Depth of installation is affected by the level of ground water. Ground water condition affects the selection of the appropriate microtunneling machine. Selection of the appropriate microtunneling machine is affected by the existence of unusual soil condition.

The effect of obstructions or unusual soil condition can be reduced by the technical support and the use of lubrication. Restricted working hours increases the use of lubrication before starting tunneling. Existence of curved alignment is not a problem with the existence of technical support and the use of lubrication.

From the previous analysis, there is dependency between each factor and other factors. The number of these dependencies on each factor is shown in Table 4. It gives an indication how sensitive the process to any change of some factors as it affects factors that depends on it. Consequently, productivity can be affected dramatically because of slight change in a certain factor. Drive length was identified to have the highest number of dependencies followed by soil conditions and lubrication and, finally, ground water and geotechnical investigations.

\section{Favorable Soil Conditions}

Every type of soil has positive and negative effects with respect to productivity. The respondents were asked to rank the soil conditions for various microtunneling operations to determine the overall favorable condition. The results of this section of the questionnaire are shown in Table 5 and Fig. 2. Sand was concluded to be the most favorable soil condition followed by silt and then clays. Boulders and backfill were the worst soil conditions with respect to microtunneling.

\section{Productivity Models}

The survey results were used as the basis for a further research. Quantity factors affecting productivity were used to develop productivity models. Data were collected from 35 projects using six different microtunneling machines in four different cities. Total number of collected data points was 17,000 data points. Every data point represents a linear meter of microtunneling drives. Sophisticated statistical techniques such as cluster analysis, multicollinearity, and best subset regression were used in analyzing the data. The following statistical models were developed for different soil types. Detailed analysis of models and factors elimination method can be visited in Hegab et al. 2006. The developed models are as follows.

For fine/soft soil

$$
\begin{aligned}
\sqrt[3]{\mathrm{TM}}= & 0.0668 L+0.00801 P+4.06 D-0.00167 T \\
& -0.000820 P \sqrt{L}+0.000411 T \sqrt{L}-0.0000001 T L^{2} \\
& -0.753 \log P L+1.07 \log T L
\end{aligned}
$$

for medium soil

$$
\begin{aligned}
\sqrt{\mathrm{TM}}= & 0.548 L-0.134 P+40.8 D-0.00897 T-0.00358 P L \\
& -0.000325 T L+0.0476 P \sqrt{L}+0.00274 T \sqrt{L} \\
& +0.000002 P L^{2}+0.000001 T L^{2}-7.20 \log T L
\end{aligned}
$$

for coarse/hard soil

$$
\begin{aligned}
\sqrt{\mathrm{TM}}= & 0.468 L-0.176 P+46.2 D-0.00502 T-0.00229 P L \\
& -0.000194 T L+0.0394 P \sqrt{L}+0.00103 \mathrm{~T} \sqrt{L} \\
& -0.000001 P L^{2}+0.000001 T L^{2}-7.27 \log P L
\end{aligned}
$$

where $\mathrm{TM}=$ driving tunneling time through different soils in minutes; $T=$ shear force of the cutter head in metric tons; $P=$ jacking force in metric tons; $D=$ machine diameter in meters; and $L=$ jacking length in meters.

\section{Conclusions}

The research has two main conclusions. It has identified and ranked the most important factors affecting the productivity of microtunneling projects, which indicates how sensitive the productivity to change in each factor. It was the basic step in mod-

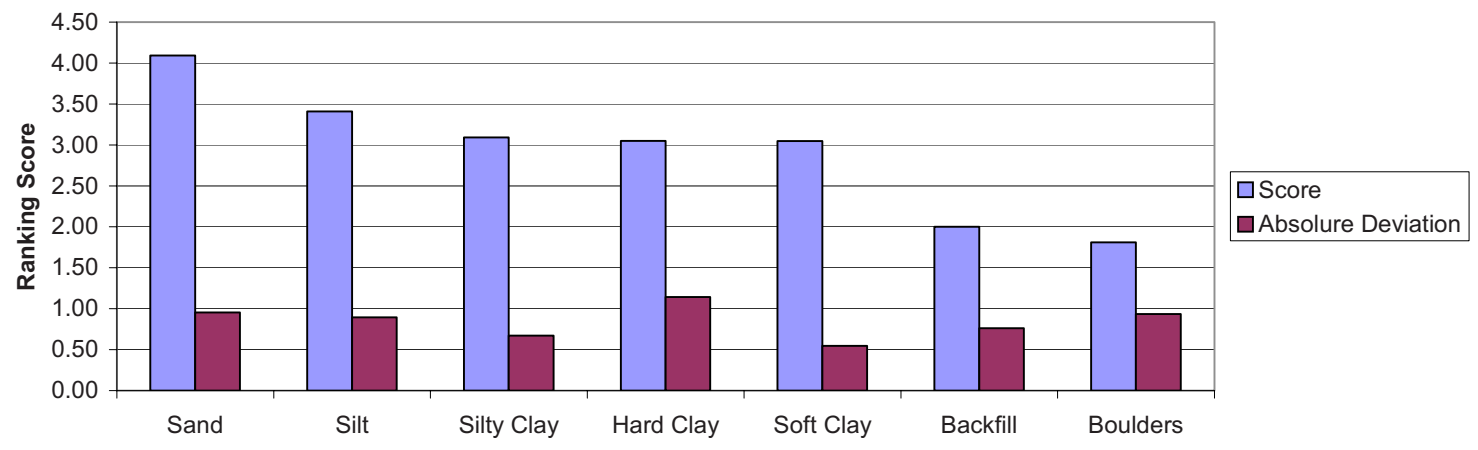

Fig. 2. Questionnaire responses of favorable soil condition for microtunneling 
eling the productivity of microtunneling projects in different soils (Hegab 2003), which is presented in a pending publication of ASCE.

The productivity of microtunneling operations depends on a large number of factors. Soil conditions, accurate geotechnical investigations, operator's experience, obstructions, use of lubrication, and the capacity of main jacks have the most impact on the productivity of microtunneling. Accordingly, the contractor should study these factors well in the bidding phase of the project because they are the keys for profitability. Most of productivity factors are interdependent, and ignoring one of them can affect the project dramatically. Knowing that sand is the most favorable soil condition for microtunneling while boulders is the worst one can help contractors recognize the difficulty of the project and adjust the bid and schedule accordingly.
This questionnaire highlighted the main factors affecting the productivity of microtunneling operation. This paper has examined the level of importance of the factors based on expert opinion and examined the importance of their relationships. Contractors, engineers, and owners should consider these factors when looking for enhancing the project productivity. This questionnaire was a step in modeling the productivity of microtunneling projects under different soil conditions (Hegab 2003).

\section{Acknowledgments}

The names of the survey participants have been kept confidential upon their request. However, the authors thankfully acknowledge those who participated in this survey for their valuable opinions and time spent in preparing their responses.

\section{Appendix I. Microtunneling Questionnaire}

This questionnaire is conducted for the purpose of a Ph.D. research. All the data will be confidential. Thank you for your participation. Your valuable experience in microtunneling is greatly appreciated. If you have any question regarding this questionnaire, please do not hesitate to contact me by telephone (701) 231-8823 or by e-mail. You can as well contact Dr. O. Salem at telephone (701) 231-7246.

The respondent

Name

Company

Address

Telephone

Fax

E-mail

Position

Company type:

$\bigcirc$ Contractor $\quad \bigcirc$ Subcontractor Owner $\quad \bigcirc$ Engineer

1. How many years have you been dealing with microtunneling?

2. Give a rank for the effect of every factor on the productivity of the microtunneling machine (M/T).

( 1 is negligible and 5 is very important)

$\begin{array}{llllll} & 2 & 3 & 4 \\ \text { 1. Cutter head shape } & 1 & 2 & 0 & 0 \\ \text { 2. Crew/operator experience } & 0 & 0 & 0 & 0 \\ \text { 3. Soil conditions } & 0 & 0 & 0 & 0\end{array}$


4. Drive length

5. Separation equipment design

6. Pipe section length

7. Shaft design (size, layout, structural integrity)

8. Slurry flow rate

9. Pipe material

10. Use of intermediate jacking station

11. Use of water jets at the excavation face (jetting)

12. Accurate geotechnical investigations

13. Depth of installation

14. Groundwater conditions

15. M/T type (slurry, EPB, pilot)

16. Obstruction or unusual soil conditions

17. Restrictions to working hours

18. Straight versus curved alignment

19. Technical support

20. Use of lubrication

21. Jacking thrust

22. Torque

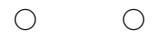

$\bigcirc$

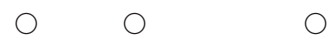

O

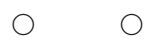

$\bigcirc$

○

23. Other

3. Please mention the dependency between the factors. If any of the following factors depends on another factor, please write the number(s) indicating the dependent factor in front of each one (multiple selections are acceptable).

E.g.

1. Cutter head shape

3

2. Crew/operator experience

3. Soil conditions

1

(There is dependency between cutter head shape and soil condition or, in other words, there is an interaction between them)

1. Cutter head shape

2. Crew/operator experience

3. Soil conditions 
4. Drive length

5. Separation equipment design

6. Pipe section length

7. Shaft design (size, layout, structural integrity)

8. Slurry flow rate

9. Pipe material

10. Use of intermediate jacking station

11. Use of water jets at the excavation face (jetting)

12. Accurate geotechnical investigations

13. Depth of installation

14. Groundwater conditions

15. M/T type (slurry, EPB, pilot)

16. Obstruction or unusual soil conditions

17. Restrictions to working hours

18. Straight versus curved alignment

19. Technical support

20. Use of lubrication

21. Jacking thrust

22. Torque

4. Rank the soil conditions ( 1 is the least favorable soil condition and 5 is the most favorable one from the productivity point of view).

$\begin{array}{lllll}1 & 2 & 3 & 4 & 5\end{array}$

Hard clay

$\bigcirc \quad 0$

$\bigcirc$

$\bigcirc$

Silty clay

Soft clay

○ 0

○

○ 0

$\bigcirc$

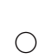

Silt

Sand

Boulders and rocks

○ $\bigcirc$

$\bigcirc$

○ 0

$\bigcirc$

○ 0

$\bigcirc$

Backfill

○

$\bigcirc$

$\bigcirc$

○

○

○

○

○

$\bigcirc$

$\bigcirc$ 


\section{Appendix II. Glossary (ISTT 1999)}

Cutter head: a rotating tool or system of tools that excavates at the face of the microtunneling bore.

Cutter shape: the actual teeth and supporting structure that is attached to the front face of the microtunneling machine. It is used to reduce the material that is being drilled or bored to sand or loose dirt so that it can be conveyed out of the hole.

Intermediate jacking station (IJS): a fabricated steel cylinder fitted with hydraulic jacks, which is incorporated into a pipeline between two pipe segments. Its function is to distribute the jacking load over the pipe string on long drives. tion.

Jacking force: force applied to pipes in a pipe jacking opera-

Jetting (water jet): a process using high pressure water to wash out the face of a utility crossing without any mechanical or hand excavation of the soils in the face. This process can be used to loosen hard soils in front face of the microtunneling machine.

Obstruction: any object or feature that lies completely or partially within the cross section of the microtunnel and prevents continued forward progress.

Slurry: a fluid, normally water, used in a closed loop system for the removal of spoil and for the balance of groundwater pressure during microtunneling.

Separation equipment: a plant that has a set of equipment (such as shakers, hydrocyclones, and cones) where excavated material is separated from the circulation slurry.

Torque: the rotary force available at the drive chuck.

Lubrication: injection of lubricants around the pipeline during tunneling.

\section{References}

Atalah, A., and Hadala, P. (1996). "Microtunneling database for the USA and Canada from 1984 to 1995." Proc., Specialty Conf.: Pipeline Crossings 1996, ASCE, 332-339.

Bain, L. J., and Engelhardt, M. (1992). Introduction to probability and mathematical statistics, 2nd Ed., Wadsworth, Belmont, Calif.

Finkbeiner, S. M., and Stevens, C. F. (1988). "Applications of quantitative measurements for assessing glutamate neurotoxicity." Proc. Natl. Acad. Sci. U.S.A., 85, 4071-4074.

Hegab, M. (2003). "Productivity modeling of microtunneling projects." Ph.D. dissertation, North Dakota State Univ., Fargo, N.D.

Hegab, M., Smith, G., and Salem, O. (2006). "Soil penetration modeling in microtunneling projects." J. Constr. Eng. Manage., 132(6), 598608.

Huber, P. (1981). Robust statistics, Wiley, New York.

International Society of Trenchless Technology (ISTT). (1999). Trenchless technology guidelines, ISTT, London.

McKim, R. (1997). "Bidding strategies for conventional and trenchless technologies considering social costs." Can. J. Civ. Eng., 24(5), 819827.

Nido, A. (1999). "Productivity projection model for microtunnelling operations based on a quantitative analysis of expert evaluation." Independent research study, Purdue Univ., West Lafayette, Ind.

Salem, O., and Hegab, M. (2001). "Risk management in trenchless technology construction.” Proc., Trenchless Egypt, No-Dig Conf., Cairo, Egypt, No-Dig, U.K.

Thompson, S., and Seber, G. (1996). Adaptive sampling, 1st Ed., Wiley, New York.

Thomson, J. C. (1993). Pipejacking and microtunnelling, Blackie Academic \& Professional, London. 